\title{
Whisker Formation in Porosity in Al Alloys
}

\author{
WILLIAM DAVID GRIFFITHS, AHMED ELSAYED, \\ and MAHMOUD AHMED EL-SAYED
}

\begin{abstract}
An examination of the fracture surfaces of tensile test bars from Al alloy castings held in the liquid state for up to 20 minutes revealed porosity which in some cases contained whisker-like features. Energy-dispersive X-ray analysis in a SEM suggested that these might be oxide whiskers forming in an oxide-related pore or double oxide film defect. Such entrainment defects (also known as bifilms) may entrap a small amount of the local atmosphere when they form and become incorporated into the liquid metal. This atmosphere may be predominantly air, which then subsequently reacts with the surrounding melt, firstly by reaction with oxygen and secondly by reaction with nitrogen. A CFD model of the heat distribution associated with the reactions between the interior atmosphere of a double oxide film defect and the surrounding liquid alloy suggested that highly localized increases in temperature, up to about $2000 \mathrm{~K}$ to $5000 \mathrm{~K}\left(1727^{\circ} \mathrm{C}\right.$ to $4727^{\circ} \mathrm{C}$ ), could occur, over a scale of a few hundred micrometers. Such localized increases in temperature might lead to the evaporation or disassociation of oxide within the pore, followed by condensation, to form the whisker structures observed. Hydrogen might also be expected to diffuse into the bifilm and may play a role in the chemical reactions associated with the development of the bifilm.
\end{abstract}

DOI: $10.1007 / \mathrm{s} 11663-016-0783-\mathrm{x}$

(C) The Author(s) 2016. This article is published with open access at Springerlink.com

\section{INTRODUCTION}

DOUBLE oxide films have become recognized as significant defects in $\mathrm{Al}$ and $\mathrm{Mg}$ alloys, leading not only to a reduction in mechanical properties but, perhaps just as detrimental, an increase in the scatter of properties. ${ }^{[1]}$ The defects are caused during the casting process when liquid metal is transferred, e.g., from a melting or holding furnace to a crucible, or during mold filling. The defects occur when the oxidized liquid metal surface is folded over onto itself, trapping the local mold atmosphere, and is then carried into the bulk liquid metal. ${ }^{[2]}$ If parts of the oxide film come into contact, it is thought that they should not bond, owing to their relatively low temperature in the liquid metal. Once the defects become submerged into the bulk liquid, they may be

WILLIAM DAVID GRIFFITHS, Senior Lecturer, is with the School of Metallurgy and Materials, College of Engineering and Physical Sciences, University of Birmingham, Edgbaston, Birmingham B15 2TT, U.K. Contact e-mail: W.D.Griffiths@bham.ac.uk AHMED ELSAYED, Research Associate, is with the Department of Mechanical Engineering, Alexandria University, Alexandria, Egypt, and also with the Department of Mechanical Engineering, Institute for Advanced Manufacturing and Engineering (AME), School of Engineering and Computing, Coventry University, Coventry CV6 5LZ, U.K. MAHMOUD AHMED EL-SAYED, Assistant Professor, is with the Department of Industrial and Management Engineering, Arab Academy for Science and Technology and Maritime Transport, Abu Qir, P.O. Box 1029, Alexandria 21599, Egypt.

Manuscript submitted April 1, 2016.

Article published online September 7, 2016. carried into the mold cavity and trapped during solidification. Their variable effect on the mechanical properties depends upon various factors such as whether the section of the casting in which they reside is under load or not in service, the orientation of the defect to the applied load, and its morphology. ${ }^{[1-3]}$

Double oxide film defects are seen as symmetrical defects on either side of a fracture surface in tensile test bars. ${ }^{[1]}$ They are identified as oxides by EDX analysis during scanning electron microscopy. Different alloys are associated with different oxides on the liquid metal surface; for example, commercial-purity $\mathrm{Al}$ should form alumina $\left(\mathrm{Al}_{2} \mathrm{O}_{3}\right)$, while a $\mathrm{Mg}$ content of between 0.02 and 1.5 wt pct has been suggested to form $\mathrm{MgAl}_{2} \mathrm{O}_{4}$ spinel. With a $\mathrm{Mg}$ content of more than $1.5 \mathrm{wt}$ pct, magnesia, $\mathrm{MgO}$, would be expected to form. ${ }^{[4]}$

Once a double oxide film defect has become incorporated into the melt, it would be expected to contain an atmosphere that would be predominantly air (although other mold gases may also be present), which would be expected to react with the surrounding liquid metal. It was proposed by Nyahumwa et al. ${ }^{[5]}$ that oxygen in the internal atmosphere would react first, followed by nitrogen. As the interior gases were consumed, the sides of the oxide film defect would come together, perhaps making the defect less detrimental. Studies by Griffiths et al. ${ }^{[6,9]}$ and El-Sayed et al. ${ }^{[8,9]}$ of the rates of consumption of air bubbles trapped in $\mathrm{Al}$ melts containing $\mathrm{Mg}$ have supported this idea, and the rates of reaction deduced from these experiments have been used to gain some understanding of the possible life cycle of a freshly created double oxide film defect.

The reactions of oxygen and nitrogen with the surrounding liquid alloy are as follows ${ }^{[10-12]}$ : 


$$
4 \mathrm{Al}+3 \mathrm{O}_{2}=2 \mathrm{Al}_{2} \mathrm{O}_{3}
$$

$$
\begin{aligned}
2 \mathrm{Al}_{2} \mathrm{O}_{3}+2 \mathrm{MgO} & =2 \mathrm{MgAl}_{2} \mathrm{O}_{4} \\
2 \mathrm{Mg}+\mathrm{O}_{2} & =2 \mathrm{MgO} \\
2 \mathrm{Al}+\mathrm{N}_{2} & =2 \mathrm{AlN}
\end{aligned}
$$

These are exothermic reactions, ${ }^{[13,14]}$ which raises the question as to where the heat evolved in these reactions diffuses to, and whether temperature increases in the vicinity of a double oxide film defect can be expected. This paper reports SEM observations of whisker-like structures found inside pores in cast $\mathrm{Al}$ alloys, together with modeling of the heat evolved by reaction of the interior gases of a double oxide film defect with the surrounding melt, to suggest an explanation for their formation.

\section{EXPERIMENTAL PROCEDURE}

\section{A. Casting Experiments}

Castings were produced from three different $\mathrm{Al}$ alloys, commercially pure $\mathrm{Al}(>99.7$ pct $\mathrm{Al}), \mathrm{Al}-7 \mathrm{Si}-0.3 \mathrm{Mg}$ (2L99), and Al-5Mg, with each alloy being expected to produce different oxide films which might have different behaviors $\left(\mathrm{Al}_{2} \mathrm{O}_{3}, \mathrm{MgAl}_{2} \mathrm{O}_{4}\right.$, and $\mathrm{MgO}$, respectively). In each experiment, about $10 \mathrm{~kg}$ of the alloy was melted and held at about $1073 \mathrm{~K}\left(800^{\circ} \mathrm{C}\right)$ under a reduced pressure of about 80 mbar for one hour, in an attempt to remove previously introduced bifilms in the melt, by expansion and flotation to the surface. ${ }^{[15,16]}$ The liquid metal was then poured from a height of about $1 \mathrm{~m}$ into a preheated investment mold, then placed in an induction furnace to stir the melt. This was intended to cause the creation and entrainment of new double oxide film defects, of a known age. The experimental procedure has been described in detail elsewhere. ${ }^{[17,18]}$

Three experiments were carried out for each alloy. In one experiment, the casting was allowed to solidify immediately to preserve any double oxide film defects created during mold filling and melt stirring. In the other two experiments, the ceramic molds were placed in a furnace at $1073 \mathrm{~K}\left(800^{\circ} \mathrm{C}\right)$ for 10 and 20 minutes, before removal and solidification. Thus any oxide films found in the solid casting in these cases could be interpreted as being about 10 and 20 minutes old respectively. The change in the hydrogen content of each melt during holding was determined using a Severn Science Hyscan H-measuring device.

After solidification, the castings were machined into rectangular test bars, of $13 \mathrm{~mm}$ width, $10 \mathrm{~mm}$ thickness, and $75 \mathrm{~mm}$ gage length, for the measurement of their tensile properties, to determine the effect on the mechanical properties of any bifilms present. The fracture surfaces of the test bars were studied using SEM coupled with EDX to investigate the effect of the holding treatment on the morphology of oxide film defects.

\section{B. Modeling of the Temperature Distribution Around a Double Oxide Film Defect}

It has been suggested that the movement of a bifilm within an Al melt could form cracks in the oxide skin, allowing the oxygen and nitrogen inside the bifilm to react with the melt. ${ }^{[11]}$ These exothermic reactions would be expected to locally raise the temperature of the oxide layer forming the bifilm and also the surrounding liquid metal, and this temperature change was modeled in 3-D using FLUENT (version 6.3.26) (a commercial CFD software).

An experimental study of the dimensions of bifilms using 3D micro X-ray tomography suggested an approximately square shape with dimensions $2.2 \times$ $2.2 \times 0.1 \mathrm{~mm}$, giving a volume of $0.48 \mathrm{~mm}^{3}$ and a surface area of $10.6 \mathrm{~mm}^{2}{ }^{[19]}$ These dimensions were adopted for this model. Due to the assumption of symmetry, only one half of the bifilm was modeled, with the plane of symmetry placed within the interior atmosphere, parallel to the oxide walls of the bifilm, as shown in Figure 1. The model consisted of three domains, representing liquid $\mathrm{Al}$, the oxide film, and the entrapped air. The liquid Al domain has the dimensions of $2.2 \times 2.2 \mathrm{~mm}$ in area and $0.5 \mathrm{~mm}$ in depth. The oxide film thickness was assumed to be $2 \mu \mathrm{m}$, and $50 \mu \mathrm{m}$ represented the entrapped air, as shown in Figure 1. The volume of air trapped in the bifilm and to be consumed was therefore $0.05 \times 2.2 \times 2.2=$ $0.242 \mathrm{~mm}^{3}$, and the surface area of the reaction was assumed to be $2.2 \times 2.2=4.84 \mathrm{~mm}^{2}$, the area of the face of the oxide layer.

Two cases were considered. In the first one, it was assumed that all reactions would occur by the rupture and resealing at a single location in the oxide film, as shown in Figure 1(a). This might arise because the region that was fractured and then resealed by the reaction between the melt and the gas inside the defect would be the weakest point in the oxide film and would have a greater tendency to tear again under the stresses associated with the movement of the bifilm within a melt. This was modeled by assuming a rupture with the dimensions of $10 \times 10 \times 2 \mu \mathrm{m}$ and a volume of $2 \times 10^{-16} \mathrm{~m}^{3}$, placed in the center of the oxide layer in the model, at which the heat source associated with the reactions was then applied.

In a second model, the reactions were considered to occur at multiple points of rupture along the oxide layer (Figure 1(b)), and the heat source assumed to be generated by the reactions was therefore applied to the entire oxide layer for one side of a bifilm, with dimensions $2.2 \mathrm{~mm} \times 2.2 \mathrm{~mm} \times 2 \mu \mathrm{m}$ and a volume of $9.68 \times 10^{-12} \mathrm{~m}^{3}$.

Table I shows the heat of formation (expressed in $\mathrm{J} \mathrm{mol}^{-1}$ of $\mathrm{O}_{2}$ or $\mathrm{N}_{2}$, of the reactants) of the different $\mathrm{Al} /$ $\mathrm{Mg}$ oxides and AlN ${ }^{[13,14]}$ together with the suggested consumption rates for the different $\mathrm{Al}$ alloys (expressed as mol m $\mathrm{m}^{-2} \mathrm{~s}^{-1}$ of $\mathrm{O}_{2}$ and $\mathrm{N}_{2}$, for the atmosphere in the bifilm), taken from Reference 9 (based on the surface 


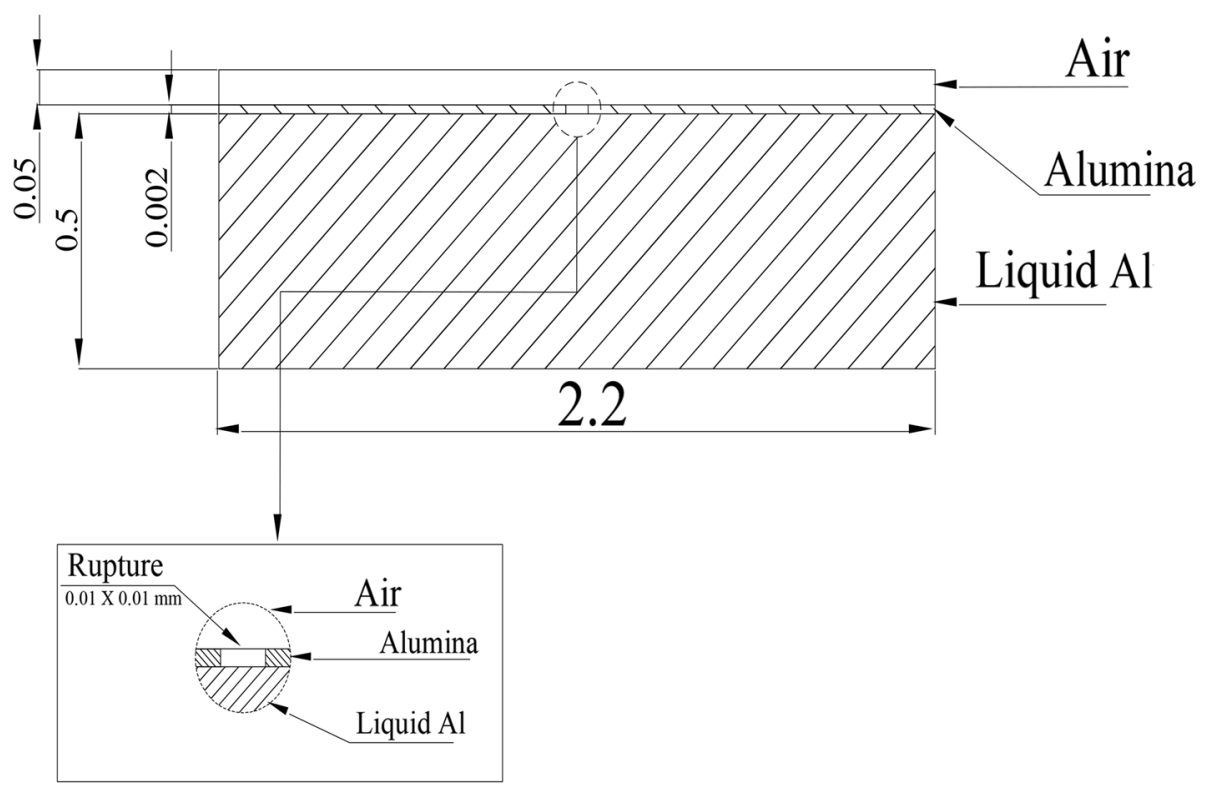

(a)

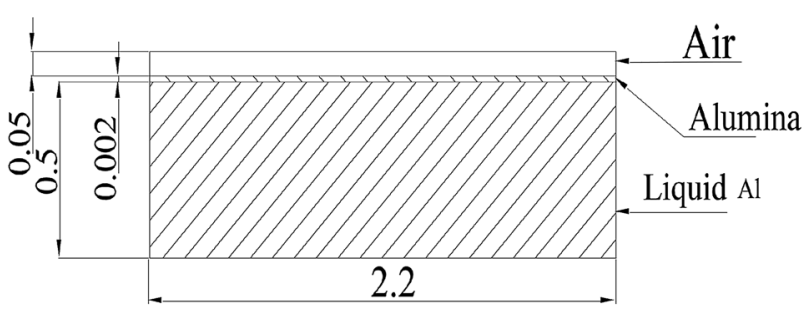

(b)

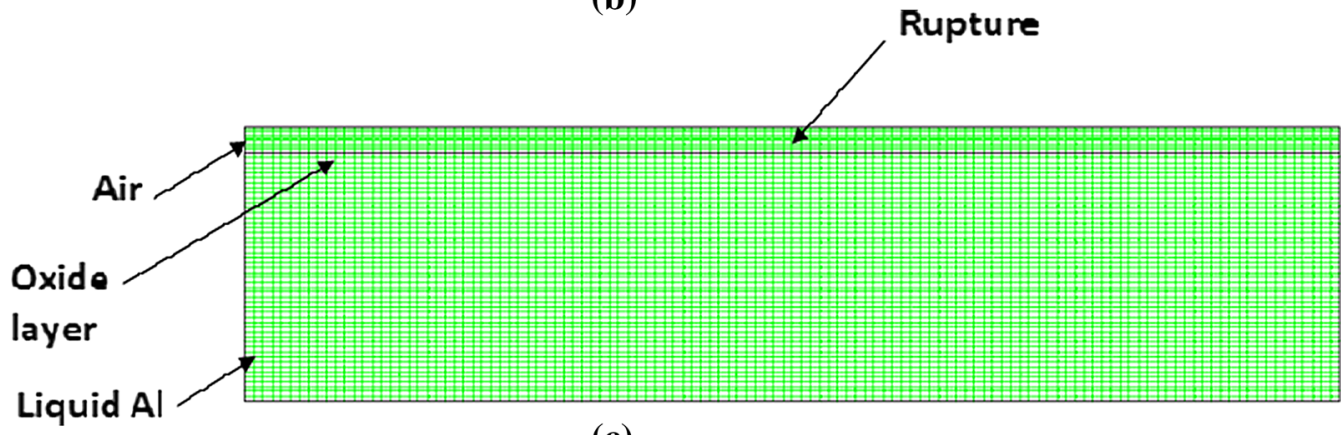

(c)

Fig. 1-Schematic illustrations of the model geometry (dimensions are in $\mathrm{mm}$ ), when $(a)$ the heat source was localized at a single point of rupture and $(b)$ the heat source was distributed uniformly over the oxide film. (c) Mesh of the geometry showing different zones in the model.

area of the reaction between the melt and the bifilm atmosphere). The consumption rates of $\mathrm{O}$ and $\mathrm{N}$ inside a bifilm of the dimensions assumed were then estimated (expressed in $\mathrm{mol} \mathrm{s}^{-1}$ ). The time required for the consumption of $\mathrm{O}$ and $\mathrm{N}$ in the different $\mathrm{Al}$ melts was taken from Reference 9 and is also given in Table I, to arrive at a rate of heat generation per unit volume, due to the consumption of oxygen and nitrogen in the different alloys, calculated for the two cases described above.

The model geometry was created using GAMBIT (version 2.3.16). The domain was divided into three zones, to represent the volume of air, oxide film, and liquid metal, as described earlier. A fourth domain was created to represent the heat source assumed to be a single point of rupture, in Case I. The horizontal faces of the four zones were first meshed using a Quad/Map scheme with a number of intervals (interval count) of 80 on each edge. The volumes of the zones were then meshed using a Hex/Cooper scheme resulting in 52,129, $36,556,110,135$, and 1770 nodes in the liquid Al, air, oxide, and rupture zones, respectively (See Figure 1(c)). The mesh density of the whole domain was $7.2 \times 10^{5}$ cells per $\mathrm{mm}^{3}$. In the model, all the outer boundaries of the different zones were set to be stationary walls with a constant temperature of 


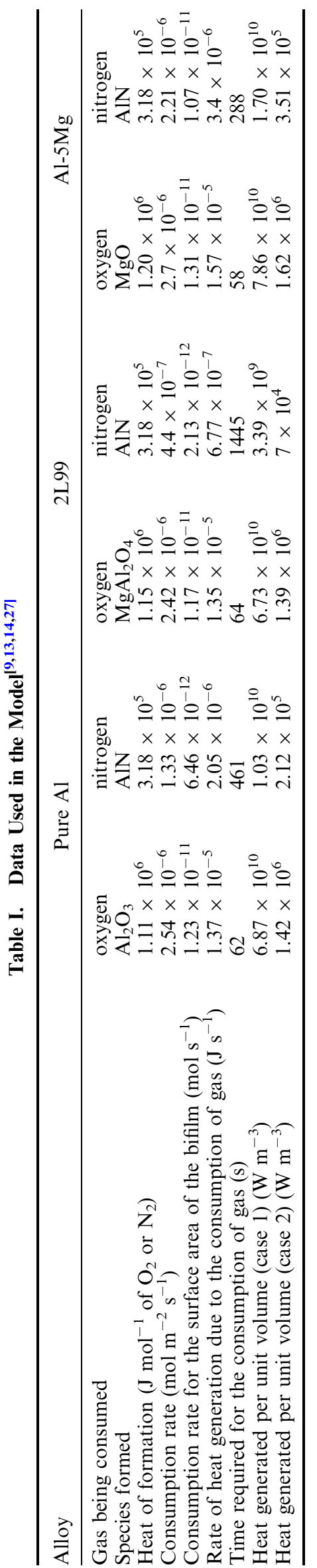

$1073 \mathrm{~K}\left(800^{\circ} \mathrm{C}\right)$. The heat transfer from the volumetric heat source applied to the oxide layer was considered to be due to conduction through the oxide zone and the convection and conduction through the air and liquid $\mathrm{Al}$ zones.

The grid was exported as a mesh file from GAMBIT into FLUENT for solution. A 3D segregated, unsteady first-order implicit solver was selected. The physical and thermal properties (e.g., viscosity, thermal conductivity, and specific heat capacity) of the different materials (liquid aluminum, alumina, spinel, $\mathrm{MgO}$, and air) were assigned to the corresponding zones. ${ }^{[20,21]}$ These values are given in Table II.

The operating pressure and initial temperature were set to $101,325 \mathrm{~Pa}(1 \mathrm{bar})$ and $1073 \mathrm{~K}\left(800{ }^{\circ} \mathrm{C}\right)$, respectively. The velocity-pressure coupling was solved using the SIMPLE algorithm. Quick Scheme was used for discretization of the momentum equation and a second-order upwind scheme was used for discretization of the energy equation. The unsteady solver was set to a 1 -second time step with a maximum number of iterations per time step of 60 .

At the end of each iteration, the residual sum for each of the conserved variables was determined. Convergence was considered to have occurred when the residuals of a variable fell below a predetermined value, $10^{-5}$, for the continuity, momentum, and energy equations. Temperatures at different locations in the domain were recorded while running the solution. These monitors were also indicators of convergence, if they did not change significantly for successive iterations. With these criteria, 60 iterations per time step were found to be sufficient for convergence of the solution.

In the model, for pure $\mathrm{Al}$ and for Case I, a volumetric heat source of $6.87 \times 10^{10} \mathrm{Wm}^{-3}$ was applied at the location of the rupture for 62 seconds, to represent the period of oxygen consumption. The heat source was then decreased to $1.03 \times 10^{10} \mathrm{Wm}^{-3}$ and applied at the same location for 461 seconds, to represent the heat evolved during the subsequent consumption of nitrogen. The heat source was then removed and the model was allowed to run for another 180 seconds before halting. In Case II, the volumetric heat source (see Table I) was applied to the volume of the half oxide layer used in the model. For 2L99 and Al-5Mg alloys, the same procedure was adopted with the appropriate values for the heat source and the corresponding application times, as shown in Table I.

\section{RESULTS}

\section{A. Microscopy}

Figure 2(a) shows a SEM image from a pore on the fracture surface of a tensile test bar of commercial-purity $\mathrm{Al}$ held in the liquid state for 20 minutes before solidification. Inside the pore, what appears to be an oxide layer seems to be entrapped between two dendrite arms, with whisker-like structures appearing to have grown from the surface of the oxide layer. EDX analysis, shown in Figure 2(b), indicated the presence 
Table II. Physical and Thermal Properties [at $\left.1073 \mathrm{~K}\left(800{ }^{\circ} \mathrm{C}\right)\right]$ of the Materials Used in the Model Zones ${ }^{[20,21]}$

\begin{tabular}{lcccc}
\hline & $\begin{array}{c}\text { Density } \\
\left(\mathrm{kg} \mathrm{m}^{-3}\right)\end{array}$ & $\begin{array}{c}\text { Thermal } \\
\text { Conductivity }\left(\mathrm{W} \mathrm{m} \mathrm{m}^{-1} \mathrm{~K}^{-1}\right)\end{array}$ & $\begin{array}{c}\text { Specific Heat } \\
\text { Capacity }\left(\mathrm{J} \mathrm{kg}^{-1} \mathrm{~K}^{-1}\right)\end{array}$ & $\begin{array}{c}\text { Viscosity } \\
\left(\mathrm{kg} \mathrm{m}^{-1} \mathrm{~s}^{-1}\right)\end{array}$ \\
\hline Alumina & 3970 & 7.2 & 1150 & $\mathrm{NA}$ \\
Spinel & 3640 & 3.1 & 1193 & $\mathrm{NA}$ \\
MgO & 3580 & 10.1 & 1267 & $\mathrm{NA}$ \\
Air & 0.40 & 0.068 & 1138 & $4.18 \times 10^{-5}$ \\
Liquid Al & 2331 & 208 & 1160 & $1.3 \times 10^{-3}$ \\
\hline
\end{tabular}

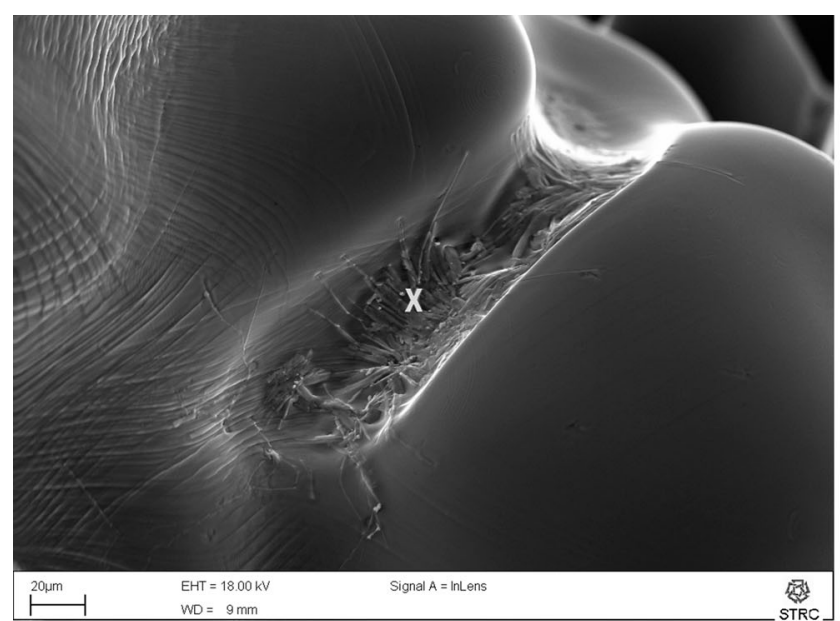

(a)

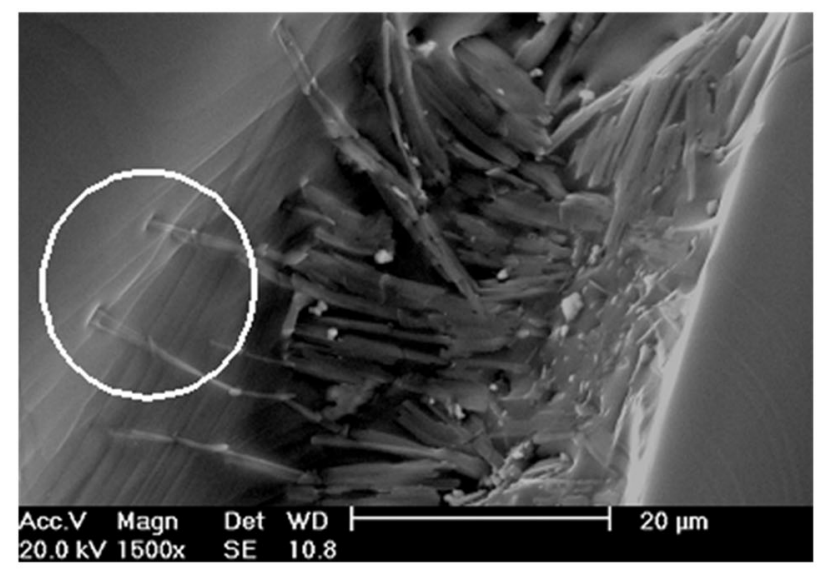

(c)

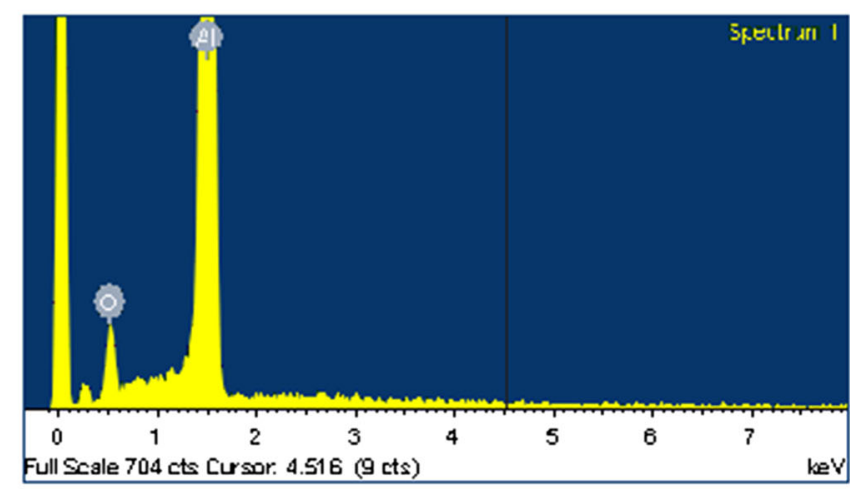

(b)

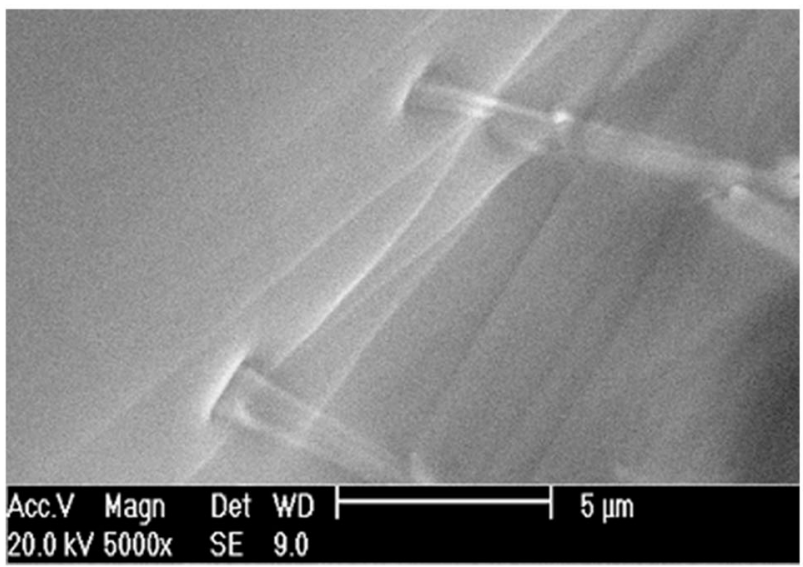

(d)

Fig. 2-(a) Whisker structures developed on an oxide layer seen on the fracture surface in commercial-purity $\mathrm{Al}$ alloy, held for 20 min in the liquid state before solidification. (b) EDX analysis at location labeled "X" in (a). (c) Magnified image of the area containing the whiskers and (d) further magnification of the area circled in (c).

of aluminum oxide. Higher magnification views of these whiskers are shown in Figures 2(c) and (d).

Two other examples of whiskers found within pores on the fracture surfaces of two tensile test bars of $\mathrm{Al}-5 \mathrm{Mg}$ alloy, also held in the liquid state for 20 minutes before solidification, are shown in Figures 3 and 4. In both figures, (a) shows a SEM image showing the whisker structure, while (b) shows a higher magnification image of the whisker. The results of EDX analysis at points $\mathrm{X} 1$ and $\mathrm{X} 2$, shown in (c) and (d), respectively, indicated the presence of $\mathrm{MgO}$.
No whiskers were found on the fracture surfaces of samples, from both commercial-purity $\mathrm{Al}$ and $\mathrm{Al}-5 \mathrm{Mg}$ alloys, either when solidified immediately or held in the liquid state for 10 minutes before solidification. Also no whisker structures were found in pores on the fracture surfaces of test bars from any of the 2L99 alloy castings.

The whiskers shown in Figures 2 through 4 may be interpretable as due to chemical reactions occurring within the pore atmosphere, resulting in the deposition of what appear to be ceramic whiskers. 


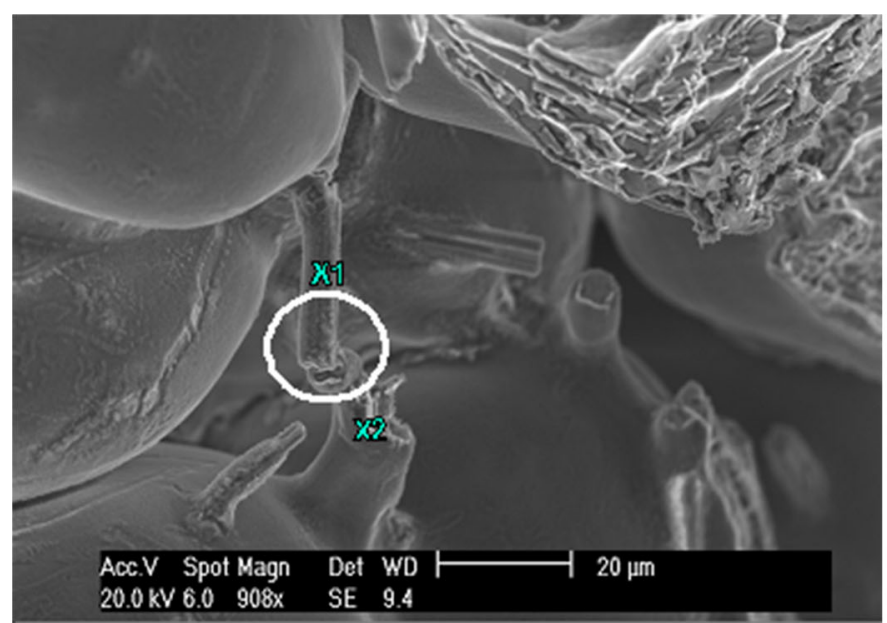

(a)

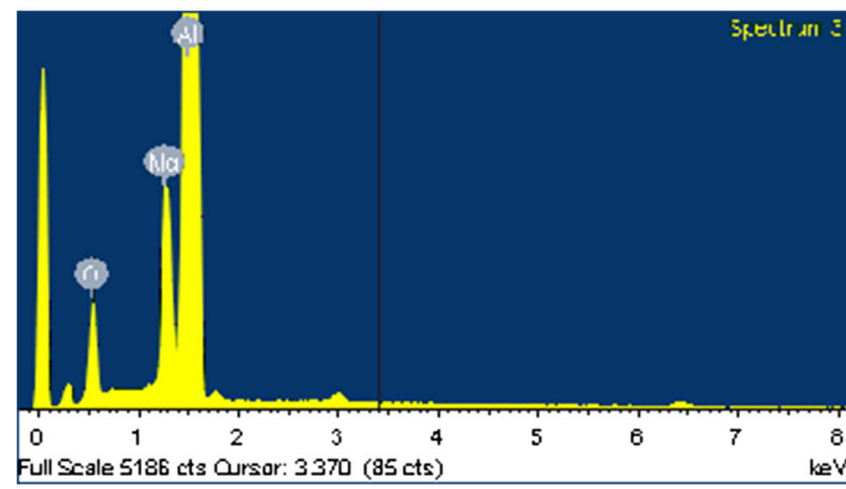

(c)

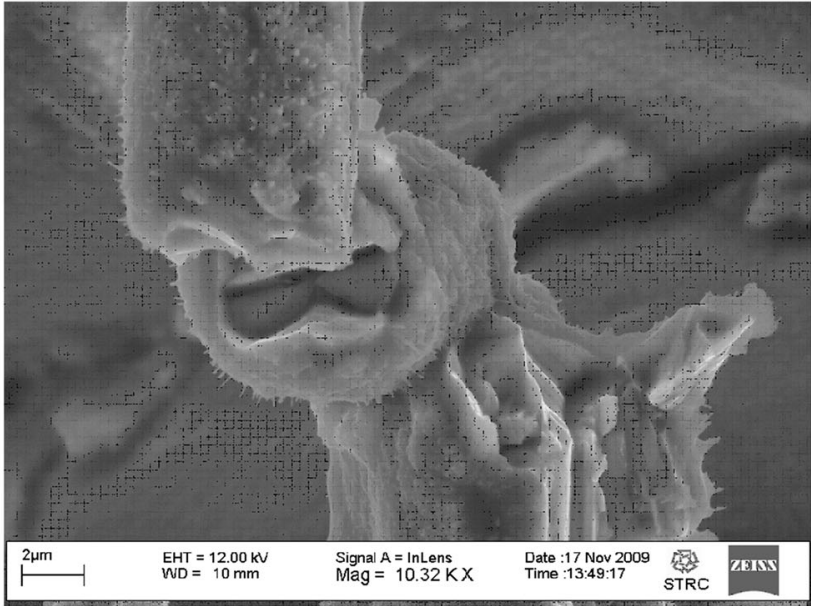

(b)

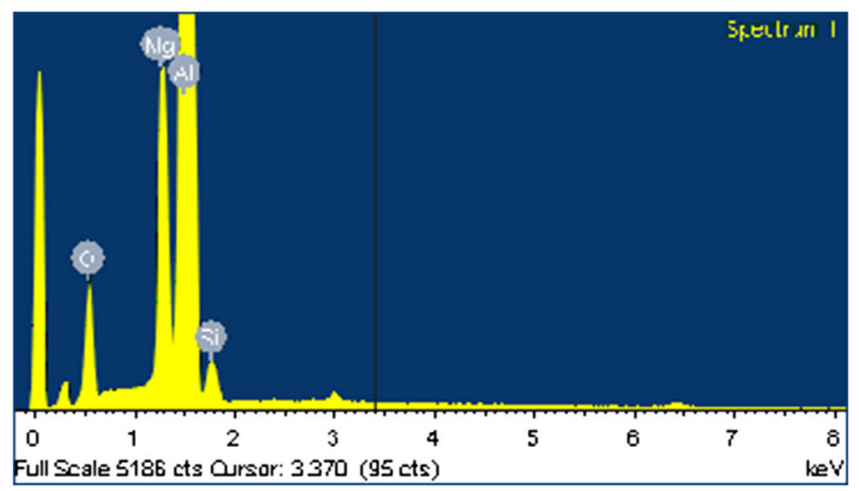

(d)

Fig. 3- (a) SEM image from the fracture surface of a test bar from an Al-5Mg alloy held for 20 min in the liquid state before solidification, showing whisker-like structures linking parts of the porosity. (b) Magnified image of the zone circled in (a). ( $c$ and $d$ ) EDX analysis of locations $\mathrm{X} 1$ and $\mathrm{X} 2$ in (a), respectively.

\section{B. Results of Modeling}

Figures 5(a) and (b) show the distribution of isotherms for an alumina double oxide film defect, across a vertical plane for the two cases, respectively (after a simulation time of 2 minutes). Figure 5(a) shows the temperature distribution when the reactions were considered to occur only at the location of a single rupture of the oxide film (Case I), for which the maximum temperature in the model at this time was predicted to be about $2600 \mathrm{~K}\left(2327{ }^{\circ} \mathrm{C}\right)$. Around the rupture location, the temperature decreased with distance and reached $1073 \mathrm{~K}\left(800{ }^{\circ} \mathrm{C}\right)$, the initial melt temperature, at a distance of about $15 \mu \mathrm{m}$ from the point of rupture.

For Case II, in which it was assumed that the heat evolved by the reactions was distributed uniformly along the oxide layer, the maximum predicted temperature after 2 minutes (see Figure 5(b)) was much lower, about $1500 \mathrm{~K}\left(1227^{\circ} \mathrm{C}\right)$, with the maximum occurring at the center of the alumina film. The temperature decreased gradually toward both ends of the modeled oxide film, where it again reached $1073 \mathrm{~K}\left(800{ }^{\circ} \mathrm{C}\right)$. The layers of air and $\mathrm{Al}$ melt adjacent to the alumina film had almost similar temperatures as predicted for the alumina film, but showed steep temperature gradients normal to the oxide film. The temperature at the upper boundary of the air zone (i.e., at the center of the assumed bifilm) was predicted to be about $1200 \mathrm{~K}\left(927^{\circ} \mathrm{C}\right)$. At a distance of about $0.4 \mathrm{~mm}$ normal to the oxide film, the temperature of the liquid $\mathrm{Al}$ had declined to reach the bulk liquid temperature of $1073 \mathrm{~K}\left(800{ }^{\circ} \mathrm{C}\right)$ (see Figure 5(b)). The distribution of temperature was similar for the three different alloys, for both modeled cases.

Figures 6(a) through (c) show the predicted change in temperature with time, for the alumina, magnesia, and spinel films, respectively, for the two cases. The maximum temperatures occurred, of course, at the times corresponding to the complete consumption of the internal atmosphere of the defects. For the alumina film (Figure 6(a)), when the heat source was applied to the location of the rupture, the temperature at this point was predicted to increase over 9 minutes to reach a maximum value of about $5000 \mathrm{~K}\left(4727^{\circ} \mathrm{C}\right)$. When the heat source was distributed over the entire $\mathrm{Al}_{2} \mathrm{O}_{3}$ film, the temperature of the alumina layer reached a maximum, again after 9 minutes, of about $2200 \mathrm{~K}\left(1927^{\circ} \mathrm{C}\right)$.

The MgO film (Figure 6(b)) showed similar behavior to that of the alumina film. The temperature increased with time to reach predicted peak values (after about 


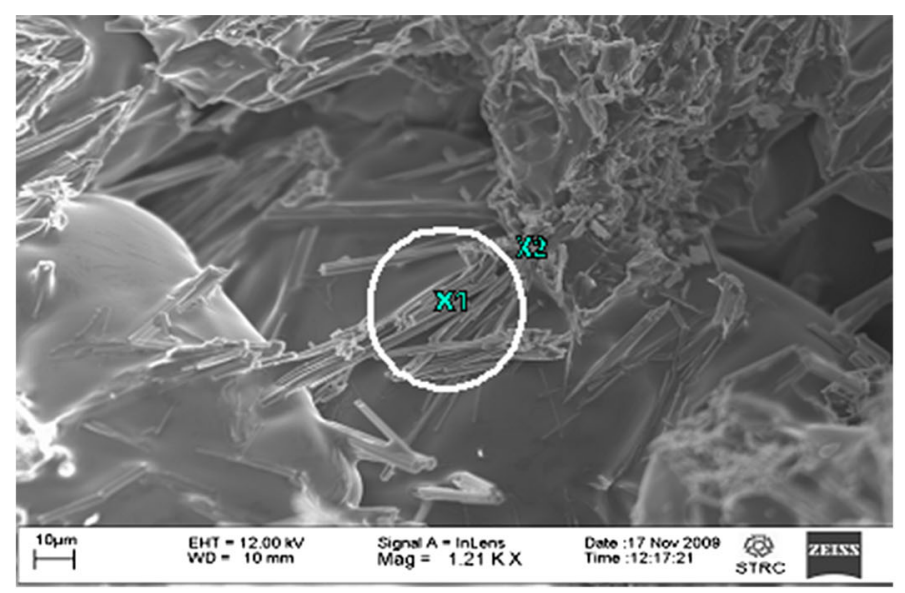

(a)

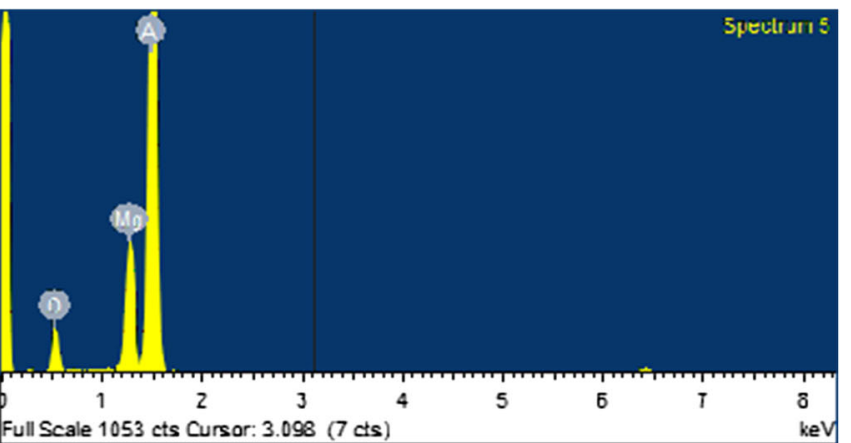

(c)

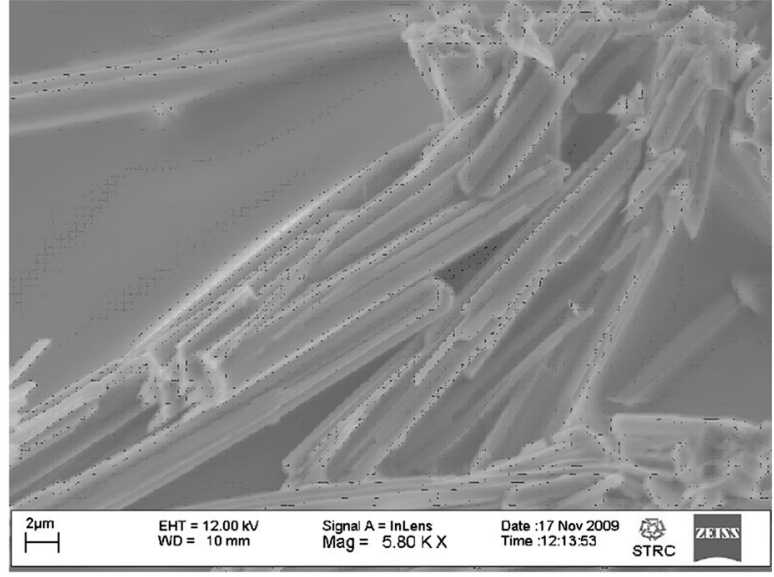

(b)

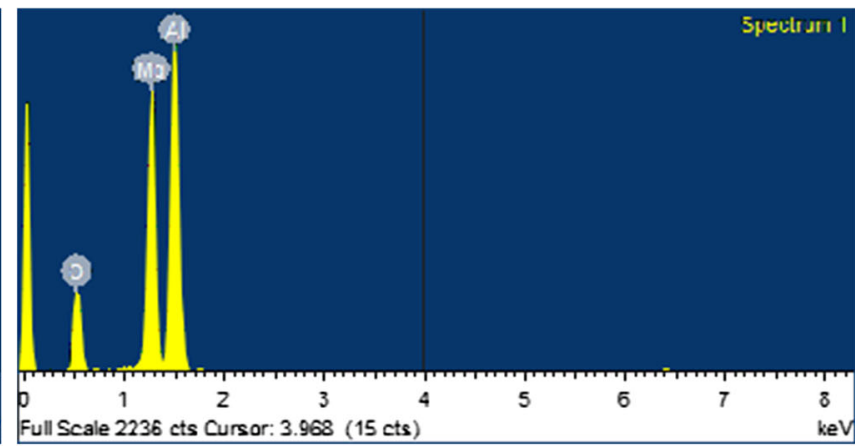

(d)

Fig. 4 - (a) SEM image of the fracture surface of a test bar from an Al-5Mg alloy held for 20 min in the liquid state before solidification, showing whisker-like structures. (b) Higher magnification image of the circled region in (a). ( $c$ and $d)$ EDX analysis of the locations labeled X1 and $\mathrm{X} 2$ in (a), respectively.

6 minutes) of about $5100 \mathrm{~K}$ and $2200 \mathrm{~K}\left(4827{ }^{\circ} \mathrm{C}\right.$ and $1927^{\circ} \mathrm{C}$ ), respectively, for the two cases when the heat source was applied at a single point of rupture or across the whole film.

For the spinel film (Figure 6(c)), the temperature increased with time to reach a maximum value of about $3000 \mathrm{~K}\left(2727^{\circ} \mathrm{C}\right)$, for the application of the heat source at a point of rupture, and about $1900 \mathrm{~K}\left(1627^{\circ} \mathrm{C}\right)$, for the application of the heat source across the whole oxide film. However, the time to reach the maximum temperature was assumed to take a longer time of about 25 minutes.

Finally, in all cases, after cessation of the application of the heat source the temperature of the oxide layer decreased as the heat was conducted away, reaching the bulk melt temperature of $1073 \mathrm{~K}\left(800{ }^{\circ} \mathrm{C}\right)$ in about 2 to 3 minutes.

\section{DISCUSSION}

The whisker-like structures found within pores on the fracture surfaces of castings from commercially pure $\mathrm{Al}$, shown in Figure 2, were found after a holding period of 20 minutes. Such structures were suggested to be alumina by EDX analysis. Comparable whiskers were also detected inside pores on the fracture surfaces of Al-5Mg castings after 20-minutes holding, as shown in Figures 3 and 4, which were demonstrated by EDX to be probably
$\mathrm{MgO}$. Previous work, involving the use of mass spectroscopy and a pore gas analyser to determine the changing composition of an air bubble held in liquid $\mathrm{Al}$ alloy melts, suggested that the internal atmosphere of an oxide-related pore should consist largely of $\mathrm{H}_{2}$ and $\mathrm{N}_{2}$. ${ }^{[6]}$ The whisker-like growths are suggestive of ceramic structures grown from a vapor phase, which suggests that the whisker-like oxide structures may have formed within oxide-related porosity that may have contained an atmosphere consisting substantially of hydrogen.

The modeling results for the three alloys suggested a significant increase in the temperature of a double oxide film defect due to heat released by the reaction between the interior atmosphere of the oxide film defect and the surrounding melt, and it is possible that this might generate the heat required to bring about the deposition of the ceramic structures from the vapor phase suggested above.

For example, it was suggested by DeVries and Sears ${ }^{[22,23]}$ that heating of an alumina substrate to temperatures of up to $2273 \mathrm{~K}\left(2000{ }^{\circ} \mathrm{C}\right)$, in the presence of hydrogen, would cause the vaporization of alumina to produce gaseous $\mathrm{Al}_{2} \mathrm{O}$ and water vapor. When the temperature was subsequently reduced to about $1873 \mathrm{~K}$ $\left(1600{ }^{\circ} \mathrm{C}\right)$, the reaction was reversed and alumina was deposited in the form of whiskers. In an experiment by Edwards and Happel, ${ }^{[24]}$ the formation of alumina whiskers on the surface of an alumina substrate was 


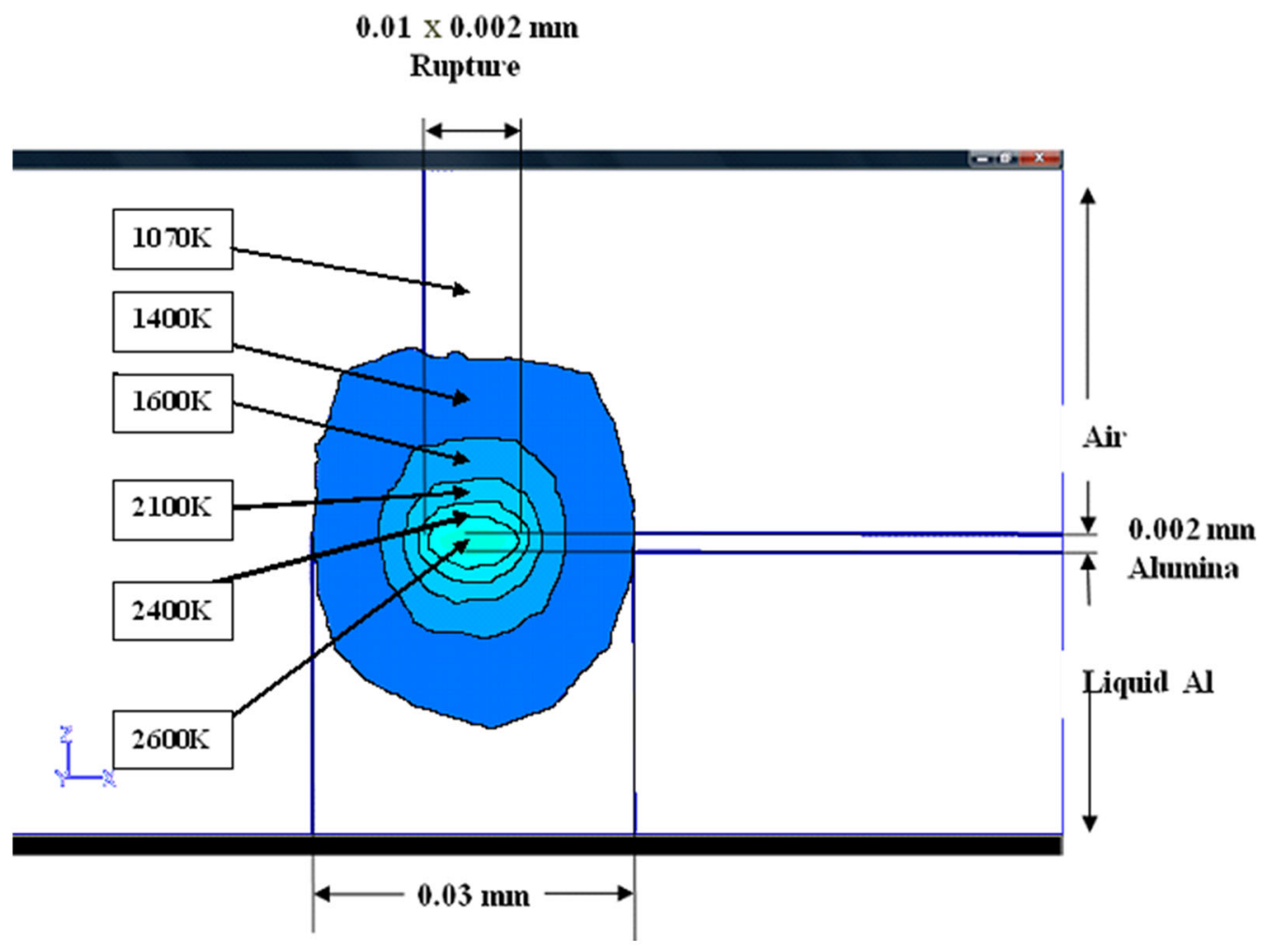

(a)

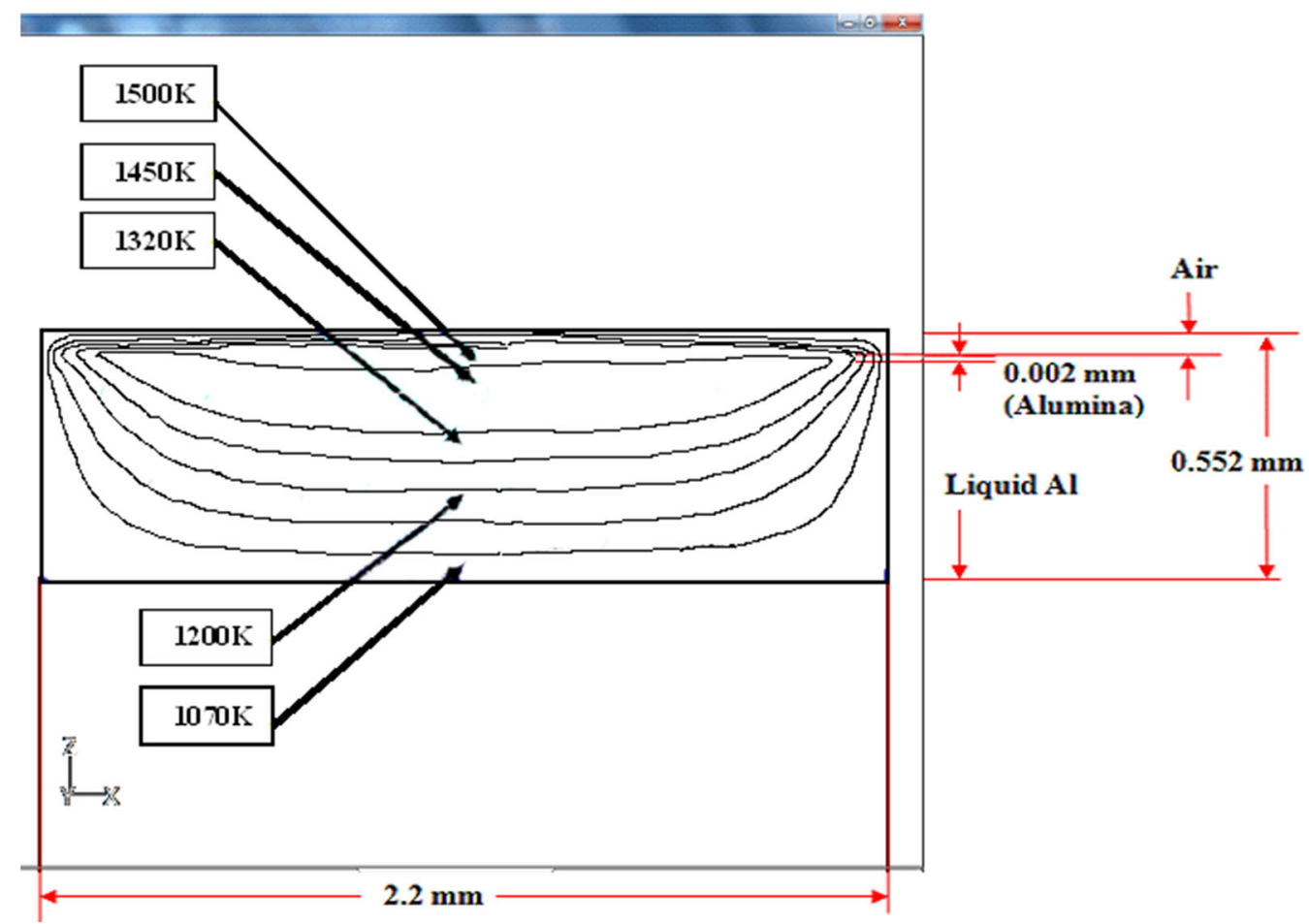

(b)

Fig. 5-Results of the model, showing (a) temperature contours after 2 min of application of the heat source at the location of a single rupture point in the alumina layer, and $(b)$ temperature contours after 2 min of application of the heat source distributed uniformly over the alumina layer.

suggested to occur, at $1673 \mathrm{~K}\left(1400{ }^{\circ} \mathrm{C}\right)$ in an atmosphere of moist hydrogen, over a period of about 2 hours. Also, Hayashi and Saito reported the formation of magnesia whiskers by a vapor phase reaction of magnesium and water vapor at $1673 \mathrm{~K}$ $\left(1400{ }^{\circ} \mathrm{C}\right)$ and at atmospheric pressure. ${ }^{[25]}$ 


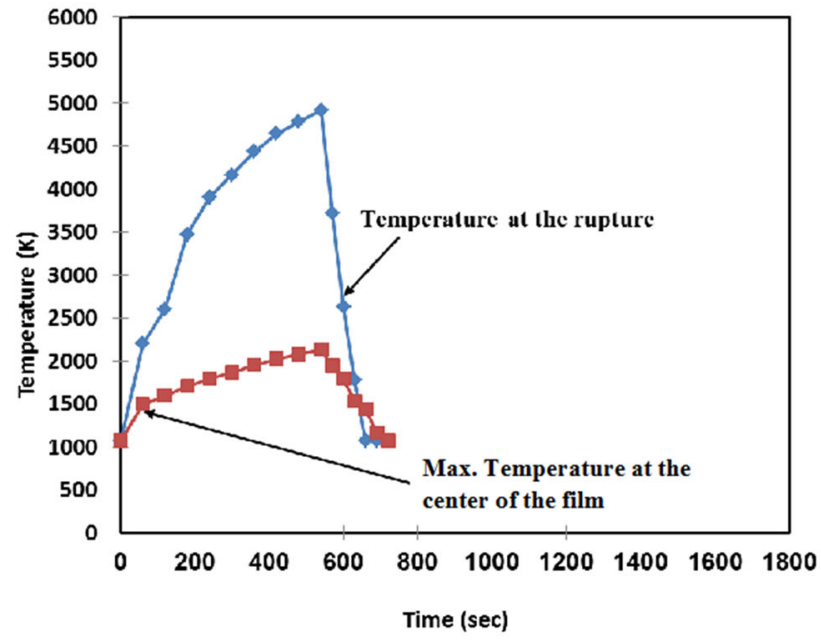

(a)

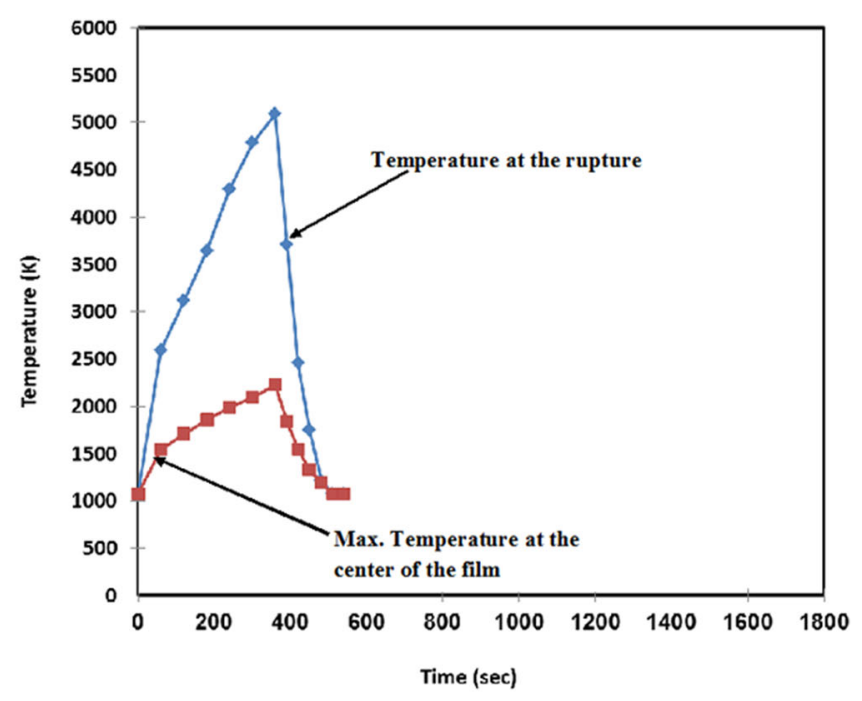

(b)

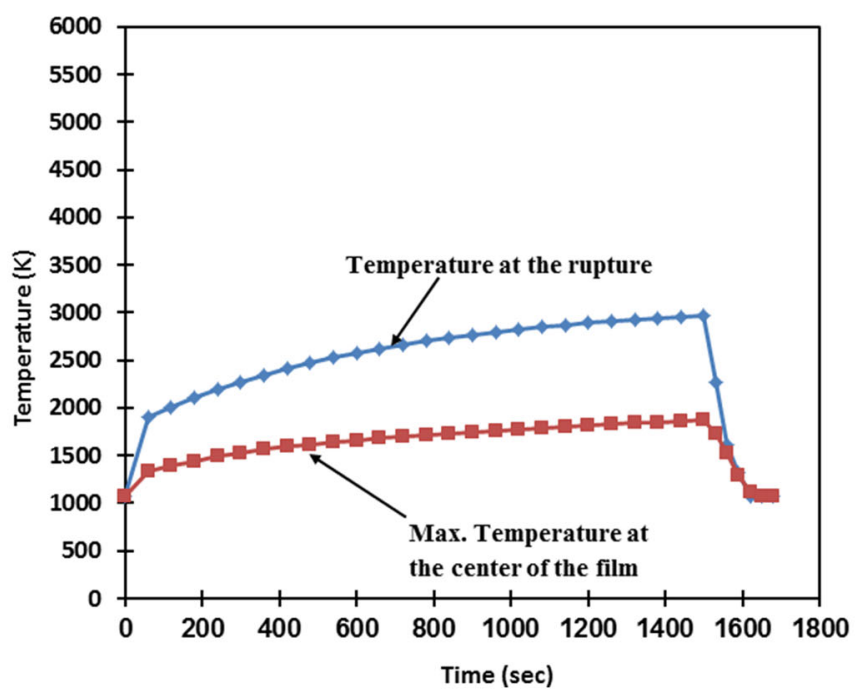

(c)

Fig. 6- Graph showing the change in maximum temperature within the oxide layer over time when the heat source was applied (i) to the location of a single point of rupture and (ii) distributed uniformly over the oxide layer. (a) For the case of pure Al, having an alumina oxide film. (b) For the case of Al-5Mg, having a magnesia oxide film. (c) For the case of an Al-Si-Mg alloy, (2L99), having a spinel oxide film.

The model suggested that, for commercially pure $\mathrm{Al}$ and $\mathrm{Al}-5 \mathrm{Mg}$ alloys, during holding of the melt, the reactions of $\mathrm{Al}$ or $\mathrm{Mg}$ with the $\mathrm{O}_{2}$ and $\mathrm{N}_{2}$ in the bifilm atmosphere may locally increase the temperature of parts of the modeled bifilm up to about $2000 \mathrm{~K}$ to $5000 \mathrm{~K}$ $\left(1727^{\circ} \mathrm{C}\right.$ to $\left.4727^{\circ} \mathrm{C}\right)$. Such increases in temperature, in addition to the diffusion of $\mathrm{H}$ into the bifilm atmosphere, could cause the partial reduction of the alumina or magnesia forming the bifilm, producing $\mathrm{Al}_{2} \mathrm{O}$ or $\mathrm{Mg}$ respectively (which would be expected to occur as a vapor phase at these temperatures), and water vapor. During solidification, if all of the $\mathrm{O}_{2}$ and $\mathrm{N}_{2}$ had been consumed, the temperature would begin to decrease, perhaps resulting in the reaction of $\mathrm{Al}_{2} \mathrm{O}$ or $\mathrm{Mg}$ with water vapor to produce the alumina and magnesia in whisker form, as observed in Figures 2 through 4.

It was suggested that a bifilm could take up to 25 minutes to lose its entire atmosphere by reaction with the surrounding melt, ${ }^{[6]}$ depending mainly upon the alloy composition, and its oxide. The absence of whiskers observed inside pores on the fracture surfaces from castings with 0 - or 10-minute holding before solidification may either indicate that they were present, but not observed, or their absence could have been due to the local temperature inside the bifilm not reaching that required for the whisker formation mechanism to operate, which might occur only after the consumption of the majority of oxygen and nitrogen inside the bifilm.

The nature of the oxide film may also have an effect on the possibility of whisker formation, as no whiskers were observed inside oxide-related pores in the case of 2L99 alloy, whatever the duration of the holding period. Previous research has suggested that the characteristics of a spinel double oxide film defect meant it would have the smallest amount of $\mathrm{H}$ diffusing into its internal atmosphere during holding. ${ }^{[7,8,26]}$ Also, the modeling 
results suggested an increase in the temperature of a spinel bifilm during holding which was around half of the increase in temperature associated with the alumina and magnesia bifilms (see Figure 6(c)), due to lower reaction rates. This might prevent the growth of whiskers associated with the spinel film due to an insufficient amount of heat and/or $\mathrm{H}$ within the bifilm atmosphere.

Apart from any effect such as the deposition of the ceramic whiskers observed, the model suggests the intriguing possibility that parts of a double oxide film defect, and its immediate locality, can experience temperature excursions of up to several thousand degrees. The boiling points of aluminum, alumina, and magnesia are $2792 \mathrm{~K}, 3250 \mathrm{~K}$, and $3873 \mathrm{~K}\left(2519^{\circ} \mathrm{C}, 2977^{\circ} \mathrm{C}\right.$, and $3600{ }^{\circ} \mathrm{C}$ ), respectively, ${ }^{[13]}$ which suggests that localized boiling of the material might occur. This is an aspect of the behavior of double oxide film defects that needs to be taken into account in order to fully understand their behavior.

\section{CONCLUSIONS}

1. Whisker-like structures of oxides were found in pores in castings of commercially pure $\mathrm{Al}$ and $\mathrm{Al}-5$ pct $\mathrm{Mg}$ alloys solidified after holding for 20 minutes in the liquid state.

2. A CFD model of the increase in temperature of an alumina, spinel, and a magnesia oxide layer (due to the formation of $\mathrm{Al}_{2} \mathrm{O}_{3}$ or $\mathrm{MgO}$, and $\mathrm{AlN}$ within a bifilm) suggested a highly localized increase of the temperature inside a bifilm that could be as high as $5000 \mathrm{~K}\left(4727^{\circ} \mathrm{C}\right)$.

3. The increase in the bifilm temperature might be sufficient to evaporate some portions of the oxides from the bifilm walls. During subsequent cooling and solidification, this material might then be redeposited in the form of ceramic (oxide) whiskers.

4. The presence of the whisker structures could perhaps be interpreted as due to chemical reactions resulting in the deposition of ceramic whiskers, which in turn suggests an atmosphere present in the pores that was superheated and rich in hydrogen.

5. With commercial-purity $\mathrm{Al}$ and $\mathrm{Al}-5 \mathrm{Mg}$ alloys, no whiskers were observed inside oxide-related pores at holding periods of less than 20 minutes. In addition, no whiskers were observed in the case of 2L99 alloy, at any duration of the holding period. It is suggested that this might be due to an insufficient amount of heat generated, and/or hydrogen present, within the bifilm gap for the whisker formation mechanisms to operate.

\section{ACKNOWLEDGMENTS}

The authors would like to gratefully acknowledge the technical assistance of Mr. Adrian Caden of the University of Birmingham and the financial and technical assistance of Professor A. Y. Kandeil of the
Arab Academy for Science, Technology and Maritime Transport, Alexandria, Egypt, and Professor H. Salem of the American University in Cairo, Egypt.

\section{OPEN ACCESS}

This article is distributed under the terms of the Creative Commons Attribution 4.0 International License (http://creativecommons.org/licenses/by/4.0/), which permits unrestricted use, distribution, and reproduction in any medium, provided you give appropriate credit to the original author(s) and the source, provide a link to the Creative Commons license, and indicate if changes were made.

\section{REFERENCES}

1. J. Campbell: Mater. Sci. Technol., 2006, vol. 22, pp. 127-45.

2. J. Campbell: Castings, 2nd ed., Butterworth-Heineman, Oxford, 2003.

3. M. El-Sayed, H. Hassanin, and K. Essa: Int. J. Cast Metal Res., 2016, In Press.

4. M.P. Silva and D.E.J. Talbot: in Proc. Conf. on Light Metals, 118th Ann. Meeting, 1989, Las Vegas, NV.

5. C. Nyahumwa, N.R. Green, and J. Campbell: AFS Trans., 1998, vol. 106, pp. 215-23.

6. W.D. Griffiths, A. Caden, and M. El-Sayed: Mater. Sci. Forum., 2014, vols. 783-786, pp. 142-47.

7. W.D. Griffiths, A.J. Caden, and M.A. El-Sayed: in Proc. Conf. on Liquid Metal Processing and Casting, 2013, Austin, Texas, Wiley, pp. 187-92.

8. M. El-Sayed, H. Salem, A. Kandeil, and W.D. Griffiths: Mater. Sci. Forum., 2013, vol. 765, pp. 260-65.

9. M. El-Sayed, H.G. Salem, A. Kandeil, and W.D. Griffiths: Metall. Mater. Trans. B, 2014, vol. 45B (4), pp. 1398-406.

10. M. Aryafar, R. Raiszadeh, and A. Shalbafzadeh: J. Mater. Sci., 2010, vol. 45 (11), pp. 3041-51.

11. R. Raiszadeh and W.D. Griffiths: Metall. Mater. Trans. B, 2006, vol. 37B, pp. 865-71.

12. L. Yang, D. Zhu, C. Xu, J. Zhang, and J. Zhang: Metall. Mater. Trans. A, 1996, vol. 27A, pp. 2094-99.

13. M.W. Chase: J. Phys. Chem. Ref. Data, 1985, vol. 14, p. 751.

14. E.A. Brandes and G.B. Brook: Smithells Metals Reference Book, 7th ed., Butterworth-Heinemann, Oxford, 1999.

15. M. El-Sayed, H. Hassanin, and K. Essa: Int. J. Adv. Manuf. Technol., 2016, In Press.

16. R. Raiszadeh and W.D. Griffiths: J. Alloy Compd., 2010, vol. 491 (1-2), pp. 575-80.

17. M. El-Sayed: Oxide Film Defects and Mechanical Properties in Aluminium Alloys, Scholar's Press, Germany, 2014.

18. M.A. El-Sayed, H.A.G. Salem, A.Y. Kandeil, and W.D. Griffiths: Metall. Mater. Trans. B, 2011, vol. 42B (6), pp. 1104-09.

19. J.M. Park: MRes Thesis, University of Birmingham, UK, 2010.

20. R.C. Reid, J.M. Prausnitz, and T.K. Sherwood: The Properties of Gases and Liquids, McGraw-Hill, New York, 1977.

21. Y.S. Touloukian: Thermophysical Properties of High Temperature Solid Materials, Macmillan, New York, 1967.

22. R.C. DeVries and G.W. Sears: J. Chem. Phys., 1959, vol. 31 (5), pp. $1256-57$.

23. G.W. Sears and R.C. DeVries: J. Chem. Phys., 1963, vol. 39 (11), pp. $2837-45$.

24. P.L. Edwards and J.R.J. Happel: J. Appl. Phys., 1962, vol. 33 (3), pp. 826-27.

25. S. Hayashi and H. Saito: J. Cryst. Growth, 1974, vols. 24-25, pp. 345-49.

26. M. El-Sayed and W.D. Griffiths: Int. J. Cast Metal Res., 2014, vol. 27 (5), pp. 282-87.

27. J.A. Shearer and O.J. Kleppa: J. Inorg. Nucl. Chem., 1973, vol. 35 (4), pp. 1073-78. 